\title{
The Pursuit of Ecotopia: Lessons from Indigenous and Traditional Societies for the Human Ecology of Our Modern World
}

Eugene N. Anderson. 2010. Praeger Publishers, Santa Barbara. Pp. 251. \$44.95 (Hardcover). ISBN 0313381305.

\author{
Reviewed by Steve Wolverton ${ }^{1}$
}

Reviewer Address: ${ }^{1}$ Environmental Archaeology, Department of Geography, University of North Texas, Denton, Texas 76203

Received: July $9^{\text {th }} 2010$

Published: August $17^{\text {rd }} 2010$

Environmentalism is rife with political correctness such that the term "human impacts" is often chastised as loaded and is replaced with softer words, such as "human-environmental interactions." There is really no place for this soft approach in Eugene Anderson's recent book The Pursuit of Ecotopia. Yet, Anderson is blunt and forceful in a respectful manner in his epic essay (or series of essays) on the state of the environmental crisis, and more precisely the place of humanity within it. The book covers political ecology, political economy, environmental injustice, morality, ethics, and traditional and local management of natural resources. It is a hefty read-honest, penetrating, unabashed, damming, inspiring, and hopeful all at once. As a result, books such as this one should put ethnobiology in the forefront of literature on the current, global environmental crisis, and it is my hope that scholars in environmental science, political ecology, environmental economics, and related disciplines will read it to see what it offers.

Throughout the book, Anderson points out successful and unsuccessful examples of environmental management. He criticizes governments that are too big, too small, and those that claim to maintain free trade but fall short. Although there are several messages throughout the book that draw on Anderson's vast experience with environmental knowledge in many cultures, worldwide, there are three that resonated deeply in my reading of it. First, Anderson discards typical notions that politics can solve modern environmental problems by demonstrating that most governments are held hostage by huge natural resource and agricultural firms that are economically more powerful than many a nation. Only individuals can overcome problems of environmental management, and to do so there must be unity. Members of societies in developed countries have much to learn regarding solidarity from traditional and
Volume 1:22-25

(C) 2010 Society of Ethnobiology

local societies (e.g., Lepofsky 2009). In particular, in local settings where natural resources, food, and space are concerned, it is much easier for people to recognize face-to-face that they are in it together. Often overlooked by scientists, economists, politicians, and other parties from developed countries is that environmental management in local settings has been effective for centuries.

Anderson conveys a belief that people must gain solidarity at the global scale to overcome current environmental abuses. It is interesting to note that throughout the book, Anderson describes problems in detail, but balances his discussion with fair objectivity. Why wouldn't big business promote environmental abuse when the current cultural system promotes values of strident individualism at the cost of common good? And yet toxic pollution that kills people, Anderson equates to toleration of fatal drive-by shootings (p. 191). Similarly, irresponsible exploitation of a finite resource that could be managed more sustainably threatens global ecology, humanity's "global life support system," and should not be tolerated ( $p$. 191). The problems are ones of scale and context; people recognize individual threats from point sources, but it is much harder to adopt a position of solidarity to confront cumulative challenges. Even environmentalists are boondoggled by individualism: "too many environmentalists think that individual actions can solve the problem. No the problem is social and political, and can only be solved by a movement that would unify people in solidarity with a common cause" (p. 189).

Second, solidarity cannot be achieved unless individual rights are protected in all societies. An important corollary is that a livable environment is a right: "if there is one human right, this is it. If resistance to direct threat is a basic right, then we all have a right—and, in fact a collective duty — to resist 
destruction of our life support system" (p. 161). Undoubtedly, adoption of such a perspective requires a change in values for many people, and this requires education as to just how it is that global ecology is a "life support system." Global solidarity of individuals concerning modern environmental problems, such as pollution, clear-cutting, over-harvesting of fish stocks, et cetera, cannot be accomplished unless environmental health is regarded as a human right. Anderson's is a no-nonsense approach. For example, he may castigate monopolistic oil firms but he also does not endorse the "indigenous above all other" perspective. Instead, environmental management must be done on a contextual basis, case-by-case. What is needed is support and infrastructure for parties (individuals) to bring their concerns and solutions to the table. Without environmental health as a right, such cannot be accomplished.

Third, Anderson labels hatred as hatred. $\mathrm{He}$ is unafraid to use and define terms, such as 'tolerance' for one another. What is meant by tolerance is open acceptance and encouragement of other's (individuals in societies) perspectives. Politicians and members of society (particularly recently in the US) are increasingly marginalized into extremist positions that reflect hatred towards the "other" (those with different values about life, environment, religion than oneself). Environmental concerns in some areas are overlooked as politicians avoid issues through divisive hateful rhetoric. Anderson uses the conservative Christian right-wing perspective as an example; not coincidentally this group is largely responsible for the rampant deregulation that allows monster-firms to control the global fate of environments (acknowledging that the general public has allowed this to happen). To overcome hatred, environmental health must be seen as a right and it must be adopted at a grass-roots level; however, a new ethic based on morality must also be advocated.

Anderson expands Leopold's Land Ethic by describing a new global ecological context and by developing reasoning for adopting a more inclusive morality. Several important principles underlie Anderson's ethic. First, if individuals matter, then "we are all in it together," which necessitates solidarity. However, what is it that we face? When Leopold wrote his Land Ethic he maintained that nature existed as a balanced system that humans perturb; nature is not separate from humanity but is a concept, environments change and are not stable, and human-influence spans the globe. Anderson states that a "new land ethic must therefore be one of managing for an unstable world system, not one of keeping our hands off (or almost off) a stable one" (p. 171). In addition Leopold entrusted communities to simply do the right thing, which has not translated into solidarity and political will. No one acts on the Land Ethic (or too few people do), and "whether the environmentalists like it or not, the world is now one big farm" (p. 170).

A new morality is required, and Anderson adopts Emmanuel Levinas' position that ethics is an interactive process-how fitting for a world that needs solidarity - "from the fear of being alone and the warmth of the active, warm interest in each other, we construct a world" (p. 178). This morality is the seat of solidarity because it requires toleration and respect for difference and interaction with other beings (human and non-human). Morality, Anderson holds, is an evolutionary force that is pragmatic, forming the basis for an ethic "that privileges long-term and wide interests over short-term, narrow ones [that] must be made explicit in particular cases" (p. 176). That is, morals and an updated ethic to support solidarity require explicit choices and love of nature. Anderson holds that an environmental ethic is multi-layered from general, widely held principles, the violation of which is easy to see, to problems of externalities that require "utilitarian calculus," to difficult choices about human preferences about what we enjoy in the world around us; "the problem is that most Americans... object to saving anything for mere beauty if it could be used for even the slightest amount of money. This appears to be true of liberals as of conservatives" (p. 199-200). Not only must our new morality adopt tolerance; we must learn to enjoy rather than simply conform because "one of the biggest problems in trying to save the environment has been public lack of willingness to act out of sheer love and delight in nature" (p. 200). Anderson deals a final blow to Calvinist morality, which prevents "acting on such grounds" by attaching morality to misery. Such Puritanism requires sameness in a world that requires diversity to survive. To conclude, Anderson makes it clear that environmental ethics in many areas of the world provide a model of what he recommends - a world in which humans enjoy the environment, which leads to solidarity and responsible community management: Ecotopia. In the West, "we have not recognized how deeply humans need a beautiful environment to be human" (p. 202).

Undoubtedly Anderson's book will be castigated by some readers as "too liberal," but there is no base to this conclusion. Anderson knows what a true conservative is, philosophically. He equally criticizes knee-jerk liberalism; the recommendations he makes 
often rely on conservative politics and (real) small government that supports the rights of individuals. The far right does not equal "conservative" and reactive liberalism is impractical. He even states that literal environmentalism is quite dangerous; "the worst thing that could possibly happen to the environment would be the world victory of such environmentalism" (p. 195). Instead local co-management of resources where individuals are invested in outcomes is the solidarity that Anderson envisions under the mantra "think globally and locally, act globally and locally" (p. 171).

Environmental philosophers may lament that they have said this all before in a variety of shapes and forms (e.g., Callicott 1989; Norton 1991; Rolston 1988; Rozzi 1999). The difference that Anderson provides is an ethnobiological context that offers a model for how things might be. Examples are consistently spattered throughout each chapter, reflecting Anderson's encyclopedic knowledge in the field. A series of examples are concentrated in Chapter 2, such as the traditional Chinese feng-shui practice of tending tree groves near settlements, which were managed for sustainable use as timber and firewood up until the Communist era. Anderson cites his own experience with the Maya of the Yucatan throughout the book for which "every aspect of cultivation and hunting is religiously_and often ritually—represented" (p. 37). One example was the " $13^{\text {th }}$ deer ceremony," which was practiced by religious leaders to give thanks and to pray for more hunting success prior to allowing additional hunting (p. 37). Countless other examples are offered, and his conclusion is that "we should be fully documenting local ecological knowledge, and, above all, management systems" as examples of how to live (more) sustainably in all environments (p. 44, emphasis in original). These management systems are not disjointed, superficial entities, and though not all traditional societies value "nature" and certainly do not all do so in the same ways when they do, traditional ecological knowledge often reflects what Wyndham (2009) terms "subtle ecologies" often running quite deep in terms of institutions, ethics, and morals (pp. 42-48). Though these subtle ecologies may result in apparently "epiphenomenal conservation" (Hunn 1982); conservation, in general, whatever the source or intention is of high value to environmentalists. In the context of ethnobiology, Anderson moves well beyond what ought to be done to how successful environmental management can be accomplished, indeed has been accomplished in many cultures; to learn from 'others' we must promote solidarity and morals and ethics that celebrate variability (differences).

As an ecologist/archaeologist who regularly interacts with environmental chemists, aquatic toxicologists, stream ecologists, other environmental scientists, and environmental philosophers I welcome Anderson's frontal ethnobiological assault on the global environmental crisis. Too often anthropologists (including ethnobiologists) tell other scholars what subjects should be of importance (Anderson touches on this on page 203); that is, we try hard to set the agenda from our self-prescribed lofty anthropological perspective, while scholars from environmental science (as one example) cannot see what concrete perspectives we bring to the table. As a result, I have been waiting for a book such as this one that brings ethnobiology to the forefront in a manner that makes sense to all parties who are concerned about global humanity and environments. Anderson's book is inclusive and should appeal to scientists, humanists, and those in between.

\section{References Cited}

Callicott, J. B. 1989. In Defense of the Land Ethic: Essays in Environmental Philosophy. State University of New York Press, Albany.

Hunn, E. S. 1982. Mobility as a Factor Limiting Resource Use in the Columbia Plateau of North America. In Resource Managers: North American and Australian Hunter-Gatherers, eds. S. M. Williams and E. S. Hunn, pp. 17-43. American Association for the Advancement of Science Selected Symposium No. 67.

Lepofsky, D. 2009. The Past, Present, and Future of Traditional Resource and Environmental Management. Journal of Ethnobiology 29:161-166.

Norton, B. 1991. Towards Unity among Environmentalists. Oxford University Press, New York.

Rolston, H. III. 1988. Environmental Ethics: Duties to and $V$ alues in the Natural World. Temple University Press, Philadelphia.

Rozzi, R. 1999. The Reciprocal Links between Evolutionary-Ecological Sciences and Environmental Ethics. Bioscience 49:911-921.

Wyndham, F. S. 2009. Spheres of Relation, Lines of Interaction: Subtle Ecologies of the Rarámuri 
Landscape in Northern Mexico. Journal of Ethnobiology 29:271-295. 